\title{
Evaluating active versus passive sources of human brucellosis in Jining City, China
}

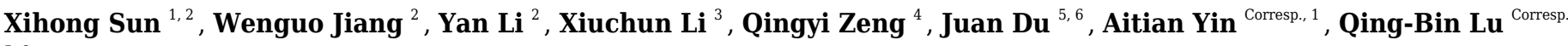 \\ 5,6 \\ ${ }^{1}$ Centre for Health Management and Policy Research, School of Public Health $\square$ Cheeloo College of Medicine, Shandong University, NHC Key Laboratory of \\ Health Economics and Policy Research (Shandong University), Jinan, Shandong, China \\ 2 Jining Center for Disease Control and Prevention, Jining, Shandong, China \\ 3 Liangshan Center for Disease Control and Prevention, Jining, Shandong, China \\ ${ }^{4}$ Yutai Center for Disease Control and Prevention, Jining, Shandong, China \\ 5 Laboratorial Science and Technology, School of Public Health, Peking University, Beijing, Beijing, China \\ 6 Center for Infectious Disease Research and Policy, Peking University Institute for Global Health, Beijing, Beijing, China \\ Corresponding Authors: Aitian Yin, Qing-Bin Lu \\ Email address: yaitian@sdu.edu.cn, qingbinlu@bjmu.edu.cn
}

Human brucellosis (HB) remains a serious public health concern owing to its resurgence across the globe and specifically in China. The timely detection of this disease is the key to its prevention and control. We sought to describe the differences in the demographics of high-risk populations with detected cases of HB contracted from active versus passive sources. We collected data from a large sample population from January to December 2018, in Jining City, China. We recruited patients that were at high-risk for brucellosis from three hospitals and Centers of Disease Control and Prevention (CDCs). These patients were classified into two groups: the active detection group was composed of individuals receiving brucellosis counseling at the CDCs; the passive detection group came from hospitals and high-risk HB groups. We tested a total of 2,247 subjects and $13.3 \%$ (299) presented as positive for $\mathrm{HB}$. The positive rates for active and passive detection groups were $20.5 \%(256 / 1,249)$ and $4.3 \%(43 / 998)$, respectively $(p<0.001)$. The detection rate of confirmed HB cases varied among all groups but was higher in the active detection group than in the passive detection group when controlled for age, sex, ethnicity, education, career, and contact history with sheep or cattle $(p<0.05)$. Males, farmers, those with four types of contact history with sheep or cattle, and those presenting fever, hyperhidrosis and muscle pain were independent factors associated with confirmed HB cases in multivariate analysis of the active detection group. Active detection is the most common method used to detect brucellosis cases and should be applied to detect HB cases early and avoid misdiagnosis. We need to improve our understanding of brucellosis for high-risk populations. Passive HB detection can be supplemented with active detection when the cognitive changes resultina from brucellosis are low. It is important that healthcare PeerJ reviewing PDF | (2020:12:56594:1:1:NEW 19 May 2021) 
providers understand and emphasis the timely diagnosis of HB. 
1 Evaluating active versus passive sources of human brucellosis in Jining City, China

3 Xihong Sun ${ }^{1,2}$, Wenguo Jiang ${ }^{2}$, Yan $\mathrm{Li}^{2}$, Xiuchun $\mathrm{Li}^{3}$, Qingyi Zeng ${ }^{4}$, Juan $\mathrm{Du}^{5,6}$, Aitian Yin ${ }^{*}$,

4 Qing-Bin $\mathrm{Lu}^{5,6^{*}}$

51 Centre for Health Management and Policy Research, School of Public Health,

6 Cheeloo College of Medicine, Shandong University, NHC Key Laboratory of Health Economics

7 and Policy Research (Shandong University), Jinan, China.

$8 \quad 2$ Jining Center for Disease Control and Prevention, Jining, PR China.

93 Liangshan Center for Disease Control and Prevention, Jining, PR China.

104 Yutai Center for Disease Control and Prevention, Jining, PR China.

115 Department of Laboratorial Science and Technology, School of Public Health, Peking

12 University, Beijing, PR China

136 Center for Infectious Disease Research and Policy, Peking University Institute for Global Health,

14 Beijing, PR China.

16 Correspondence Author:

17 Aitian Yin, Email: yaitian@sdu.edu.cn

18 Qing-Bin Lu, Email: qingbinlu@bjmu.edu.cn 


\section{Abstract}

Human brucellosis (HB) remains a serious public health concern owing to its resurgence across the globe and specifically in China. The timely detection of this disease is the key to its prevention and control. We sought to describe the differences in the demographics of high-risk populations with detected cases of $\mathrm{HB}$ contracted from active versus passive sources. We collected data from a large sample population from January to December 2018, in Jining City, China. We recruited patients that were at high-risk for brucellosis from three hospitals and Centers of Disease Control and Prevention (CDCs). These patients were classified into two groups: the active detection group was composed of individuals receiving brucellosis counseling at the CDCs; the passive detection group came from hospitals and high-risk HB groups. We tested a total of 2,247 subjects and $13.3 \%$ (299) presented as positive for HB. The positive rates for active and passive detection groups were 20.5\% $(256 / 1,249)$ and 4.3\% (43/998), respectively $(p<0.001)$. The detection rate of confirmed HB cases varied among all groups but was higher in the active detection group than in the passive detection group when controlled for age, sex, ethnicity, education, career, and contact history with sheep or cattle $(p<0.05)$. Males, farmers, those with four types of contact history with sheep or cattle, and those presenting fever, hyperhidrosis and muscle pain were independent factors associated with confirmed HB cases in multivariate analysis of the active detection group. Active detection is the most common method used to detect brucellosis cases and should be applied to detect HB cases early and avoid misdiagnosis. We need to improve our understanding of brucellosis for high-risk populations.

41 Passive HB detection can be supplemented with active detection when the cognitive changes 
42 resulting from brucellosis are low. It is important that healthcare providers understand and 43 emphasis the timely diagnosis of HB. 


\section{Introduction}

Human brucellosis (HB) is one of the most understudied tropical diseases. It is caused by the genus Brucella and results in large economic losses in the livestock industry and incredible illness in humans who contract the disease [1-3]. The disease is transmitted to humans through close contact with sick animals or the consumption of contaminated raw meat or dairy products $[4,5]$. The threat of brucellosis varies among occupational groups and the general population [6].

Brucellosis is the most prevalent and tenth most prevalent disease among impoverished populations in a study of 76 animal diseases and syndromes, respectively [7]. HB patients present with fever, sweating, fatigue, osteoarticular pain $[8,9]$ and a variety of other complications if not treated in a timely manner [10]. Chronic HB results in a wide range of pathological conditions, including spondylitis, endocarditis, and meningoencephalitis, and can affect most organs [11]. HB remains one of the most significant public health concerns in the world. The World Health Organization (WHO) estimates that a quarter of cases are unreported with 500,000 registered cases per year. The number of unreported cases with unspecified clinical symptoms is estimated to be ten times higher than this figure [12]. HB has been on the rise since 2000 and is the only traditional statutory infectious disease in China where the current incidence level is higher than the historical record. Brucellosis morbidity has increased since the middleand late-1990s and is one of the top ten total cases of Class A and B national notifiable infectious diseases reported in the mainland of China $[13,14]$. Shandong was among the top 10 provinces reporting cases of $\mathrm{HB}$ but the disease has been reported in all cities in Shandong province since 2005 [15]. It is crucial to reduce this disease's morbidity through early detection and treatment. 
HB is often misdiagnosed, or the diagnosis is delayed due to the disease's atypical symptoms [16]. Cases that are not diagnosed and treated in a timely manner will become chronic and reoccur, so a timely diagnosis is necessary.

The Jining CDC and county-level CDC agencies monitor HB cases in accordance with the requirements of the Shandong CDC in China. These centers have assisted medical institutions in the diagnosis and treatment of HB for 6 consecutive years since 2013. CDC agencies provide serological testing and individual brucellosis counseling when HB is suspected. Patients presenting clinical symptoms may choose to go to the hospital to be tested and treated. High-risk populations are administered regular tests by the CDC for routine monitoring since they are considered to be passive sources of the disease. We conducted this study to evaluate the effectiveness of HB disease-detection using active sources, as determined by individual brucellosis counseling, and passive sources, based on hospital and CDC reporting.

\section{Materials and Methods}

\section{Study population}

We enrolled participants from different testing sources who tested for HB from January to December 2018, in Jining City (Figure 1). We obtained 1,249 participants from the eight CDC centers in Jining City. Participants were tested to determine whether they were active HB cases. These subjects were classified as the active detection group. The other 998 participants were obtained from the three hospitals or CDC staff using passive means, such as a medical diagnosis $(n=480)$ or staff reporting for HB disease detection $(n=518)$. These cases were classified as the 
87 passive detection group and were obtained from suspected cases that were diagnosed in the

88 hospital or from high-risk rural groups identified through CDC surveillance.

\section{Case definition and data collection}

Brucellosis cases were subject to a defined brucellosis diagnosis (2012 edition) [17]. Suspected cases were identified as being any patient with acute or insidious fever, clinical manifestations of HB, and an epidemiological link with infected animals, contaminated food, or contact with a confirmed case. Confirmed cases were defined as having a titer of greater than 1:100 in the testtube agglutination test (SAT), or a patient sample titer of more than 1:50 with a course of disease lasting more than 1 year. We collected a blood sample of at least $3 \mathrm{~mL}$ from each participant using a vacutainer needle. We performed the Rose Bengal plate test (RBPT) and serum agglutination test (SAT) as previously reported [1]. All the reagents were configured and provided by the Shandong CDC.

A self-designed questionnaire was used to collect information, including socio-demographic characteristics, animal exposure, and clinical manifestations (Supplemental Table 1).

\section{Data management and analysis}

Data was entered using EpiData 3.1 software. We performed a descriptive analysis of the independent variables for age, sex, nation, education, career, and history of contact. Quantitative variables were expressed as mean with standard deviation (SD) or median with interquartile range (IQR) according to the normality of the variable. Categorical data were analyzed using a chi-square or Fisher exact test. Univariate analysis was done to evaluate the associations between patients' characteristics and other variables. Covariates associated with $p$ value $\leq 0.2$ in the 
108

109

110

111

112

113

114

115

116

117

118

119

120

121

122

123

124

125

126

127

128

univariate analysis were entered into a multivariate logistic regression model with the stepwise

method to obtain the final predictive model of covariates independently associated with $\mathrm{HB}$. We

estimated the odds ratio (OR) and 95\% confidence interval (95\% CI). The area under the curve

(AUC) was used to evaluate the prediction accuracy of the model by receiver operating

characteristic curve (ROC) analysis. A two-sided $p$ value of less than 0.05 was considered

significant. All statistical analyses were done using SPSS software (version 22.0).

\section{Ethics statement}

The research protocol was approved by the Peking University Institutional Review Board (IRB00001052-20008). The Research Ethics Committee waived the informed consent requirement because data were legally obtained from the CDC. All the data were analyzed anonymously.

\section{Results}

\section{Participant characteristics}

The median age of the study participants was 48 (IQR 37-56) years and there were 1,504 $(66.9 \%)$ males studied (Table 1). The majority $(2,174,96.7 \%)$ of the patients were of Han nationality and 1,195 (53.2\%) participants had a median education level (with 9 years education). Approximately half of the participants $(1,121,49.9 \%)$ were farmers and 1,565 $(69.7 \%)$

participants had contact history with sheep or cattle. There were significant differences in age, ethnicity, education, career, and contact history with sheep or cattle between the active and passive detection groups and the participants from the hospital and CDC in the passive detection 
129 group (all $p<0.05)$. There were more clinical manifestations, including fever, arthralgia,

130 debilitation, hyperhidrosis and muscle pain, observed in the active detection group than in the

131 passive detection group $(p<0.05)$.

\section{Detection of $\mathbf{H B}$}

133 Among the 2,247 participants tested for HB, 299 (13.3\%, 95\% CI 11.9\%-14.8\%) were positive

134 and confirmed as having HB. Positive HB cases in the active and passive detection groups were

$13520.5 \%(256 / 1,249,95 \%$ CI $18.3 \%-22.8 \%)$ and $4.3 \%(43 / 998,95 \%$ CI $3.1 \%-5.8 \%)$, respectively

$136(p<0.001)$. The percentage of positive HB tests varied for all participants, although there were

137 more positive cases in the active detection group than in the passive detection group when

138 accounting for age, sex, ethnicity, education, career, and contact history with sheep or cattle

$139(p<0.05)$ (Table 2$)$. There was an increase in positive HB tests as age increased and years of

140 education decreased either in the active or passive detection group ( $p<0.001$ for both). Male

141 participants of Hui ethnicity who were farmers had higher percentages of positive HB tests in the

142 active detection group, which was similar to the passive detection group results. The percentage

143 of positive HB tests due to contact with sheep or cattle was $16.0 \%$ (95\% CI $14.3 \%-18.0 \%$,

144 which was greater than the 7.0\% (95\% CI 5.2\%-9.2\%) among those with no contact. Exposure to

145 animal slaughter showed the highest percentage of positive HB tests $(21.1 \%, 95 \%$ CI $16.3 \%$ -

$14626.5 \%)$, followed by exposure through sales (18.5\%, 95\% CI 12.7\%-25.7\%), processing $(17.4 \%$,

147 95\% CI 9.3\%-28.4\%), and cultivation (14.3\%, 95\% CI 12.3\%-16.4\%). Similar results were

148 observed among the two detection groups.

149 There was a $7.7 \%(95 \%$ CI 5.5\%-10.5\%) positive HB rate obtained from the hospital among the 
150 passive detection group, which was greater than the $1.2 \%(95 \%$ CI $0.4 \%-2.5 \%)$ obtained from

151 the $\mathrm{CDC}(p<0.001)$. The former was higher than the latter with variations in age, sex, ethnicity,

152 education, career, and contact history with sheep or cattle but most of the differences were not

153 significant due to the small sample size.

154 Participants with hyperhidrosis tended to have the highest percentage of positive HB tests

$155(30.0 \%)$, followed by muscle pain (28.4\%), arthralgia (20.9\%), debilitation (20.0\%), and fever

$156(19.3 \%)$. These results were mirrored in the active detection group. Positive HB tests in the

157 passive detection group, including arthralgia (16.8\%), muscle pain (14.7\%), hyperhidrosis

$158(13.5 \%)$, debilitation (13.0\%) and fever (6.3\%), were lower than in the active detection group.

\section{Factors associated with the risk of $\mathrm{HB}$}

Multivariate analysis determined that the male sex, farmer, four types of contact history with sheep or cattle, and the presentation of fever, hyperhidrosis, and muscle pain were independently-associated factors with confirmed HB. The active detection group's population source with an AUC of $0.802(0.777-0.827)$ (all $p<0.05)$ is shown in Table 3. Selling lamb and beef presented the highest risk of $\mathrm{HB}(\mathrm{OR}=3.54,95 \% \mathrm{CI} 2.06-6.08)$ in the four types of contact history with sheep or cattle. HB risk factors in the active detection group were the male sex, farmer, two types of contact history with sheep or cattle (slaughter and selling), and the presentation of fever, arthralgia and debilitation with an AUC of 0.760 (95\% CI 0.732-0.788)

(Table 3). HB risk within the passive detection group was significantly associated with younger age, cultivation of sheep or cattle, and arthralgia with an AUC of 0.673 (95\% CI 0.639-0.706) (all $p<0.05$ ). The cultivation of sheep or cattle and hyperhidrosis were associated with the risk of 
171

172

173

174

175

176

177

178

179

180

181

182

183

184

HB infection in the passive detection group (Supplemental Table 2).

\section{Discussion}

$\mathrm{HB}$ is a major public health crisis in China. Although its true incidence remains largely unknown, it is conservatively estimated to vary from less than 0.03 to more than 160 individuals per $100,000[16,19,20]$. It is important to have early detection and treatment of suspected cases. We investigated whether the detection rate of $\mathrm{HB}$ was higher in the active detection group than in the passive detection group. The active detection group was typically aware of the CDC's role as an institution for the detection of brucellosis, suggesting that the active detection method was better able to detect HB based on greater HB awareness for this high-risk population.

A meta-analysis reported low levels of awareness and knowledge of HB among high-risk groups in Asia and Africa [21], which was thought to be affected by many factors and is an obstacle for public health. Raising awareness of brucellosis is of great significance for controlling HB. HB prevention was publicized to high-risk populations in the study area to assist in early detection and improve the awareness of HB. Those who were knowledgeable about HB were more likely to use a detection service when clinical symptoms that may be related to HB first appeared. This might be due to the fact that the positive rate was high than among the highrisk population in the active detection group. Thus, active detection is effective for the early detection of HB and publicity and education about HB may be effective in the affected areas.

We found a much lower HB detection rate in the passive detection group, including two different participant sources from hospitals and the local CDC. However, the cause of the low 
192

detection rate of $\mathrm{HB}$ between participants from these two sites may be different. The participants from hospitals had similar clinical symptoms but had less contact history with sheep or cattle compared to the participants from the local CDC. This result revealed a low detection rate and may cause a high rate of HB misdiagnosis based solely on clinical manifestation. Participants from the local CDC, however, had a higher frequency of contact history with sheep or cattle but seldom presented with clinical manifestations of HB compared to the participants from hospitals. These results revealed a low detection rate of HB based on contact history with sheep or cattle. Active detection methods avoid the disadvantages of the two passive detection methods and should be utilized on a larger scale. Active detection is also an important way to detect cases by doctors from hospitals, considering the $7.7 \%$ detection rate in the hospital. Primary healthcare workers should be aware of the symptoms of acute and chronic brucellosis when treating patients [22]. The passive detection of HB by the CDC was more successful in a specific population. Our findings showed that sex, career, contact history with sheep or cattle, and the presentation of specific symptoms (fever, hyperhidrosis and muscle pain) were HB risk factors. This is in agreement with findings from other studies [23-25].

Males had the highest disease incidence which may be a reflection of their occupational exposure to livestock in a pastoral economy where females typically have less exposure to livestock [26]. Farmers, who were typically older, developed HB more frequently. It is common for the elderly in rural areas in northern China to raise cattle and sheep through family farming. Our results indicated that efforts, such as increased publicity, education for farmers in contact with cattle, and raising awareness of disease prevention through personal protection, must be 
213 taken for the high-risk population.

214 Brucellosis is one of the most common zoonotic infections and contact with sheep or cattle is

215 the most important HB risk factor. Of the four types of contact history with sheep or cattle, the

216 sale of livestock showed the highest $\mathrm{OR}$ of $\mathrm{HB}$, which may be related to longer exposure time to

217 lamb or beef. Slaughtering and processing also showed higher ORs than cultivation. The HB

218 detection rates in the slaughter, selling, and processing population will be lower when the

219 detection of Brucella before slaughter is improved.

220 We analyzed the characteristics of a high-risk population to improve the use of limited

healthcare resources and achieve better prevention and control of $\mathrm{HB}$ as diagnosing Brucella in

the laboratory is not in wide use. It is necessary to improve the monitoring of those with clear

occupational exposure history, especially those with clinical symptoms such as hyperhidrosis for

better passive detection. Patients can improve their awareness of HB through health education

and then proceed to active detection methods for better early diagnosis. Meeting the medical

needs of active cases is the priority for treatment of HB. Behavioral intervention should be

strengthened to improve treatment compliance and prevent chronic cases and recurrence of the

disease. The two detection methods have different focuses in the prevention and control of HB.

Passive detection mode sensitivity is low, but it is an important supplement when the cognitive

impairment of brucellosis is still low. The current brucellosis surveillance pattern in China

includes a passive surveillance system based on the epidemic and an active surveillance system

in key areas that include monitoring stations [27]. It is necessary to choose the appropriate

detection strategy of HB to improve the accuracy of monitoring data.

Peer) reviewing PDF | (2020:12:56594:1:1:NEW 19 May 2021) 
234 Our study provides valuable information about HB detection in Jining City, however, there

235 were some limitations. First, our study did not account for more high-risk population for HB in

236 the community when the population did not visit the health facilities including hospitals and

237 CDCs. Second, we did not investigate the subjects' awareness and knowledge of HB, which may

be related to the risk of contracting HB. Third, we did not culture for Brucella spp. to give a gold standard result, which may have a certain bias on our reported prevalence.

We determined three measures for the control and prevention of $\mathrm{HB}$ in this region. First, the

public should be provided with more health education to improve the level of self-protection and

the awareness of timely diagnosis and treatment. Second, hospital healthcare providers should be

more aware of HB for a timely and accurate diagnosis. Third, the CDC, as the prevention and

control department of HB, should improve the breadth and depth of brucellosis detection and

screening to accurately diagnosis HB cases.

246

247

248

249

250

251

252

253

254

\section{Conclusion}

$\mathrm{HB}$ is a serious public-health problem owing to its resurgence in China and across the globe. We clearly demonstrated that the active detection model more accurately detects cases of HB than the passive detection model. We also revealed that those who had contact with sheep or cattle had the highest risk of contracting HB. These results may help policy makers develop appropriate prevention and control strategies. 
255

256

257

258

259

260

261

262

263

264

265

266

267

268

269

270

271

272

273

274

275

276

277

278

279

280

281

282

283

284

285

286

287

288

289

290

291

292

293

294

\section{References}

1. Ariza J, Bosilkovski M, Cascio A, Colmenero JD, Corbel MJ, Falagas ME, Memish ZA, Roushan MR, Rubinstein E, Sipsas NV, Solera J, Young EJ, Pappas G. Perspectives for the treatment of brucellosis in the 21st century: the Ioannina recommendations. PLoS Med. 2007;4(12):e317. Epub 2007/12/29. doi: 10.1371/journal.pmed.0040317. PubMed PMID: 18162038; PubMed Central PMCID: PMCPMC2222927.

2. Franco MP, Mulder M, Gilman RH, Smits HL. Human brucellosis. Lancet Infect Dis. 2007;7(12):775-86. Epub 2007/11/30. doi: 10.1016/S1473-3099(07)70286-4. PubMed PMID: 18045560. 3. Mableson HE, Okello A, Picozzi K, Welburn SC. Neglected zoonotic diseases-the long and winding road to advocacy. PLoS Negl Trop Dis. 2014;8(6):e2800. Epub 2014/06/06. doi:

10.1371/journal.pntd.0002800. PubMed PMID: 24901769; PubMed Central PMCID: PMCPMC4046968.

4. Deng Y, Liu X, Duan K, Peng Q. Research Progress on Brucellosis. Curr Med Chem.

2019;26(30):5598-608. Epub 2018/05/11. doi: 10.2174/0929867325666180510125009. PubMed PMID: 29745323.

5. Dadar M, Shahali Y, Whatmore AM. Human brucellosis caused by raw dairy products: A review on the occurrence, major risk factors and prevention. Int J Food Microbiol. 2019;292:39-47. Epub 2018/12/21. doi: 10.1016/j.ijfoodmicro.2018.12.009. PubMed PMID: 30572264.

6. Chen S, Zhang H, Liu X, Wang W, Hou S, Li T, Zhao S, Yang Z, Li C. Increasing threat of brucellosis to low-risk persons in urban settings, China. Emerg Infect Dis. 2014;20(1):126-30. Epub 2014/01/01. doi: 10.3201/eid2001.130324. PubMed PMID: 24377827; PubMed Central PMCID: PMCPMC3884711.

7. Molyneux D, Hallaj Z, Keusch GT, McManus DP, Ngowi H, Cleaveland S, Ramos-Jimenez P, Gotuzzo E, Kar K, Sanchez A, Garba A, Carabin H, Bassili A, Chaignat CL, Meslin FX, Abushama HM, Willingham AL, Kioy D. Zoonoses and marginalised infectious diseases of poverty: where do we stand? Parasit Vectors. 2011;4:106. Epub 2011/06/16. doi: 10.1186/1756-3305-4-106. PubMed PMID: 21672216; PubMed Central PMCID: PMCPMC3128850.

8. Zhen Q, Lu Y, Yuan X, Qiu Y, Xu J, Li W, Ke Y, Yu Y, Huang L, Chen Z. Asymptomatic brucellosis infection in humans: implications for diagnosis and prevention. Clin Microbiol Infect. 2013;19(9):E395-7. Epub 2013/05/15. doi: 10.1111/1469-0691.12250. PubMed PMID: 23668532.

9. Zheng R, Xie S, Lu X, Sun L, Zhou Y, Zhang Y, Wang K. A Systematic Review and Meta-Analysis of Epidemiology and Clinical Manifestations of Human Brucellosis in China. Biomed Res Int. 2018;2018:5712920. Epub 2018/06/01. doi: 10.1155/2018/5712920. PubMed PMID: 29850535; PubMed Central PMCID: PMCPMC5937618.

10. Breivik H, Collett B, Ventafridda V, Cohen R, Gallacher D. Survey of chronic pain in Europe: prevalence, impact on daily life, and treatment. Eur J Pain. 2006;10(4):287-333. Epub 2005/08/13. doi: 10.1016/j.ejpain.2005.06.009. PubMed PMID: 16095934.

11. Pappas G, Akritidis N, Bosilkovski M, Tsianos E. Brucellosis. N Engl J Med. 2005;352(22):2325-36. Epub 2005/06/03. doi: 10.1056/NEJMra050570. PubMed PMID: 15930423.

12. FAO, WOAH \& WHO. Brucellosis in humans and animals 2006 [2006/7/1]. Available from: https://www.who.int/csr/resources/publications/Brucellosis.pdf. 
295 13. Lai S, Zhou H, Xiong W, Gilbert M, Huang Z, Yu J, Yin W, Wang L, Chen Q, Li Y, Mu D, Zeng L, 296 Ren X, Geng M, Zhang Z, Cui B, Li T, Wang D, Li Z, Wardrop NA, Tatem AJ, Yu H. Changing 297 Epidemiology of Human Brucellosis, China, 1955-2014. Emerg Infect Dis. 2017;23(2):184-94. Epub 298 2017/01/19. doi: 10.3201/eid2302.151710. PubMed PMID: 28098531; PubMed Central PMCID: 299 PMCPMC5324817.

300 14. Wang Y, Xu C, Zhang S, Wang Z, Zhu Y, Yuan J. Temporal trends analysis of human brucellosis 301 incidence in mainland China from 2004 to 2018. Sci Rep. 2018;8(1):15901. Epub 2018/10/28. doi:

302 10.1038/s41598-018-33165-9. PubMed PMID: 30367079; PubMed Central PMCID: PMCPMC6203822. 303 15. Yang L, Bi ZW, Kou ZQ, Li XJ, Zhang M, Wang M, Zhang LY, Zhao ZT. Time-series analysis on 304 human brucellosis during 2004-2013 in Shandong Province, China. Zoonoses Public Health. 305 2015;62(3):228-35. Epub 2014/07/22. doi: 10.1111/zph.12145. PubMed PMID: 25043064.

306 16. Pappas G, Papadimitriou P, Akritidis N, Christou L, Tsianos EV. The new global map of human 307 brucellosis. Lancet Infect Dis. 2006;6(2):91-9. Epub 2006/01/28. doi: 10.1016/S1473-3099(06)70382-6. 308 PubMed PMID: 16439329.

309 17. National Health Commission of China.Brucellosis Diagnosis and Treatment Guide 2012 [updated 310 2012/10/8; cited 2012 2012/10/8]. Available from:

311 http://www.nhc.gov.cn/xxgk/pages/viewdocument.jsp?dispatchDate=\&staticUrl=/zwgkzt/wsbysj/201210/

312 56110.shtml\&wenhao=\%E5\%8D \%AB\%E5\%8A\%9E\%E5\%8C \%BB\%E6\%94\%BF\%E5\%8F\%91\%E3\%8

$313 \quad 0 \% 942012 \% \mathrm{E} 3 \% 80 \% 95117 \% \mathrm{E} 5 \% 8 \mathrm{~F} \% \mathrm{~B} 7 \&$ utitle=\%E5\%8D $\% \mathrm{AB} \% \mathrm{E} 7 \% 94 \% 9 \mathrm{~F} \% \mathrm{E} 9 \% 83 \% \mathrm{~A} 8 \% \mathrm{E} 5 \% 8 \mathrm{~A}$

$314 \% 9 \mathrm{E} \% \mathrm{E} 5 \% 85 \% \mathrm{AC} \% \mathrm{E} 5 \% 8 \mathrm{E} \% 85 \% \mathrm{E} 5 \% 85 \% \mathrm{~B} 3 \% \mathrm{E} 4 \% \mathrm{BA} \% 8 \mathrm{E} \% \mathrm{E} 5 \% 8 \mathrm{D} \% \mathrm{~B} 0 \% \mathrm{E} 5 \% 8 \mathrm{~F} \% 91 \% \mathrm{E} 5 \% \mathrm{~B} 8 \%$

$315 \quad 3 \% \mathrm{E} 9 \% \mathrm{~B} 2 \% 81 \% \mathrm{E} 6 \% \mathrm{~B} 0 \% 8 \mathrm{~F} \% \mathrm{E} 8 \% 8 \mathrm{~F} \% 8 \mathrm{C} \% \mathrm{E} 7 \% 97 \% 85 \% \mathrm{E} 8 \% \mathrm{AF} \% 8 \mathrm{~A} \% \mathrm{E} 7 \% 96 \% 97 \% \mathrm{E} 6 \% 8 \mathrm{C} \% 87 \% \mathrm{E}$ 316 5\%8D\%97\%ЕF\%BC\%88\%Е8\%AF\%95\%Е8\%A1\%8C\%ЕF\%BC\%89\%Е7\%9A\%84\%Е9\%80\%9A\%Е7

$317 \% 9 \mathrm{~F} \% \mathrm{~A} 5$ \&topictype $=$ \&topic $=$ \&publishedOrg $=\% \mathrm{E} 5 \% 8 \mathrm{C} \% \mathrm{BB} \% \mathrm{E} 6 \% 94 \% \mathrm{BF} \% \mathrm{E} 5 \% 8 \mathrm{~F} \% \mathrm{~B} 8 \&$ indexNum= $318 \quad 000013610 / 2012-02132 \&$ manuscriptId=56110.

319 18. Alton GG, Jones LM, Pietz DE. Laboratory techniques in brucellosis. Monogr Ser World Health 320 Organ. 1975;(55):1-163. Epub 1975/01/01. PubMed PMID: 812265.

321 19. Lai S, Zhou H, Xiong W, Gilbert M, Huang Z, Yu J, Yin W, Wang L, Chen Q, Li Y, Mu D, Zeng L, 322 Ren X, Geng M, Zhang Z, Cui B, Li T, Wang D, Li Z, Wardrop NA, Tatem AJ, Yu H. Changing 323 Epidemiology of Human Brucellosis, China, 1955-2014. Emerg Infect Dis. 2017 Feb;23(2):184-194.

324 Epub 2017/02/X. doi: 10.3201/eid2302.151710. PMID: 28098531;

325 20. Wang Y, Wang Y, Zhang L, Wang A, Yan Y, Chen Y, Li X, Guo A, Robertson ID. An

326 epidemiological study of brucellosis on mainland China during 2004-2018.Transbound Emerg Dis. 2020 327 Oct 28. Epub 2020/10/28. doi: 10.1111/tbed.13896.PubMed PMID:33118288 .

328 21. Zhang N, Zhou H, Huang DS, Guan P. Brucellosis awareness and knowledge in communities 329 worldwide: A systematic review and meta-analysis of 79 observational studies. PLoS Negl Trop Dis. 330 2019;13(5):e0007366. Epub 2019/05/03. doi: 10.1371/journal.pntd.0007366. PubMed PMID: 31048848; 331 PubMed Central PMCID: PMCPMC6497230.

332 22. Yumuk Z, O'Callaghan D. Brucellosis in Turkey -- an overview. Int J Infect Dis. 2012;16(4):e228333 35. Epub 2012/02/16. doi: 10.1016/j.ijid.2011.12.011. PubMed PMID: 22333223.

334 23. Cao MZ, Yang YH, Chen ZT, Zhao P, He LL. An analysis of influencing factors for brucellosis in 335 major occupational groups in Bayannur, China. Zhonghua Lao Dong Wei Sheng Zhi Ye Bing Za Zhi. 
336 2017;35(6):440-3. Epub 2017/08/07. doi: 10.3760/cma.j.issn.1001-9391.2017.06.010. PubMed PMID:

33728780821.

338 24. Cash-Goldwasser S, Maze MJ, Rubach MP, Biggs HM, Stoddard RA, Sharples KJ, Halliday JEB, 339 Cleaveland S, Shand MC, Mmbaga BT, Muiruri C, Saganda W, Lwezaula BF, Kazwala RR, Maro VP, 340 Crump JA. Risk Factors for Human Brucellosis in Northern Tanzania. Am J Trop Med Hyg.

341 2018;98(2):598-606. Epub 2017/12/13. doi: 10.4269/ajtmh.17-0125. PubMed PMID: 29231152; PubMed 342 Central PMCID: PMCPMC5929176.

343 25. Alkahtani AM, Assiry MM, Chandramoorthy HC, Al-Hakami AM, Hamid ME. Sero-prevalence and 344 risk factors of brucellosis among suspected febrile patients attending a referral hospital in southern Saudi

345 Arabia (2014-2018). BMC Infect Dis. 2020;20(1):26. Epub 2020/01/11. doi: 10.1186/s12879-020-4763-Z. 346 PubMed PMID: 31918671; PubMed Central PMCID: PMCPMC6953129.

347 26. Makita K, Fevre EM, Waiswa C, Kaboyo W, De Clare Bronsvoort BM, Eisler MC, Welburn SC.

348 Human brucellosis in urban and peri-urban areas of Kampala, Uganda. Ann N Y Acad Sci.

349 2008;1149:309-11. Epub 2009/01/06. doi: 10.1196/annals.1428.015. PubMed PMID: 19120236.

350 27. Dong SB, Jiang H, Wang LP. Progress in research and practice of brucellosis surveillance in China.

351 Zhonghua Liu Xing Bing Xue Za Zhi. 2019;40(7):870-4. Epub 2019/07/31. doi: 10.3760/cma.j.issn.0254352 6450.2019.07.025. PubMed PMID: 31357814. 


\section{Table $\mathbf{1}$ (on next page)}

The characteristics of the recruited participants from different sources 
Table 1. The characteristics of the recruited participants from different sources

\begin{tabular}{|c|c|c|c|c|c|c|c|}
\hline \multirow[b]{2}{*}{ Characteristics } & \multirow{2}{*}{$\begin{array}{c}\text { Total } \\
(\mathrm{N}=2247)\end{array}$} & \multirow{2}{*}{$\begin{array}{c}\text { Active } \\
(n=1249)\end{array}$} & \multirow{2}{*}{$\begin{array}{l}\text { Passive } \\
(\mathrm{n}=998)\end{array}$} & \multirow[b]{2}{*}{$p$} & \multicolumn{3}{|c|}{ Passive } \\
\hline & & & & & $\begin{array}{l}\text { From hospital } \\
\qquad(\mathrm{n}=480)\end{array}$ & $\begin{array}{l}\text { From CDC } \\
\qquad(\mathrm{n}=518)\end{array}$ & $p$ \\
\hline Age, year, median (IQR) & $48(37-56)$ & $46(35-56)$ & $48(39-56)$ & $0.016^{*}$ & $49(40-60)$ & $48(38-55)$ & $0.059^{*}$ \\
\hline$\leq 45$ & $959(42.7)$ & $563(45.1)$ & $396(39.7)$ & $<0.001^{\#}$ & $181(37.7)$ & $215(41.5)$ & $<0.001^{\#}$ \\
\hline $45 \sim 60$ & $900(40.1)$ & $461(36.9)$ & $439(44.0)$ & & $183(38.1)$ & $256(49.4)$ & \\
\hline$>60$ & $388(17.3)$ & $225(18)$ & $163(16.3)$ & & $116(24.2)$ & $47(9.1)$ & \\
\hline Sex & & & & $0.528^{\#}$ & & & $<0.001^{\#}$ \\
\hline Male & $1504(66.9)$ & $843(67.5)$ & $661(66.2)$ & & $280(58.3)$ & $381(73.6)$ & \\
\hline Female & $743(33.1)$ & $406(32.5)$ & $337(33.8)$ & & $200(41.7)$ & $137(26.4)$ & \\
\hline Ethnicity & & & & $0.001^{\#}$ & & & $0.004^{\#}$ \\
\hline Han & $2174(96.7)$ & $\begin{array}{l}1195 \\
(95.7)\end{array}$ & $979(98.1)$ & & $473(98.5)$ & $506(97.7)$ & \\
\hline Hui & $73(3.2)$ & $54(4.3)$ & $19(1.9)$ & & $7(1.5)$ & $12(2.3)$ & \\
\hline Education & & & & $0.001^{\#}$ & & & $<0.001^{\#}$ \\
\hline Under junior middle school & $633(28.2)$ & $379(30.3)$ & $254(25.5)$ & & $167(34.8)$ & $87(16.8)$ & \\
\hline Junior middle school & $1195(53.2)$ & $619(49.6)$ & $576(57.7)$ & & $201(41.9)$ & $375(72.4)$ & \\
\hline Above junior middle school & $419(18.7)$ & $251(20.1)$ & $168(16.8)$ & & $112(23.3)$ & $56(10.8)$ & \\
\hline Career & & & & $<0.001^{\#}$ & & & $<0.001^{\#}$ \\
\hline Famer & $1121(49.9)$ & $740(59.3)$ & $381(38.2)$ & & $221(46)$ & $160(30.9)$ & \\
\hline Worker & 709 (31.6) & $267(21.4)$ & $442(44.3)$ & & $107(22.3)$ & $335(64.7)$ & \\
\hline Children/Student & $54(2.4)$ & $31(2.5)$ & $23(2.3)$ & & $23(4.8)$ & $0(0)$ & \\
\hline Veterinarian & $59(2.6)$ & $36(2.9)$ & $23(2.3)$ & & $1(0.2)$ & $22(4.3)$ & \\
\hline Other & $304(13.5)$ & $175(14)$ & $129(12.9)$ & & $128(26.7)$ & $1(0.2)$ & \\
\hline
\end{tabular}




\begin{tabular}{lccccccc}
\hline Contact history of sheep or cow & $1565(69.7)$ & $637(63.8)$ & $928(74.3)$ & $<0.001^{\#}$ & $135(28.1)$ & $502(96.9)$ & $<0.001^{\#}$ \\
$\quad$ Cultivation & $1135(50.5)$ & $507(50.8)$ & $628(50.3)$ & $0.806^{\#}$ & $105(21.9)$ & $402(77.6)$ & $<0.001^{\#}$ \\
Slaughter & $266(11.8)$ & $76(7.6)$ & $190(15.2)$ & $<0.001^{\#}$ & $10(2.1)$ & $66(12.7)$ & $<0.001^{\#}$ \\
Selling & $151(6.7)$ & $49(4.9)$ & $102(8.2)$ & $0.002^{\#}$ & $8(1.7)$ & $41(7.9)$ & $<0.001^{\#}$ \\
Process & $69(3.1)$ & $29(2.9)$ & $40(3.2)$ & $0.685^{\#}$ & $15(3.1)$ & $14(2.7)$ & $0.691^{\#}$ \\
Clinical manifestation & $1435(63.9)$ & $957(76.6)$ & $478(47.9)$ & $<0.001^{\#}$ & $476(99.2)$ & $2(0.4)$ & $<0.001^{\dagger}$ \\
Fever & $1020(45.4)$ & $608(48.7)$ & $412(41.3)$ & $<0.001^{\#}$ & $412(85.8)$ & $0(0)$ & $<0.001^{\dagger}$ \\
Arthralgia & $623(27.7)$ & $468(37.5)$ & $155(15.5)$ & $<0.001^{\#}$ & $155(32.3)$ & $0(0)$ & $<0.001^{\dagger}$ \\
Debilitation & $465(20.7)$ & $357(28.6)$ & $108(10.8)$ & $<0.001^{\#}$ & $106(22.1)$ & $2(0.4)$ & $<0.001^{\dagger}$ \\
Hyperhidrosis & $340(15.1)$ & $266(21.3)$ & $74(7.4)$ & $<0.001^{\#}$ & $74(15.4)$ & $0(0)$ & $<0.001^{\dagger}$ \\
Muscle pain & $327(14.6)$ & $259(20.7)$ & $68(6.8)$ & $<0.001^{\#}$ & $66(13.8)$ & $2(0.4)$ & $<0.001^{\dagger}$ \\
Other & $135(6.0)$ & $68(5.4)$ & $67(6.7)$ & $0.208^{\#}$ & $67(14.0)$ & $0(0)$ & $<0.001^{\dagger}$ \\
\hline
\end{tabular}

2 IQR, interquartile range. " compared by Mann-Whitney U test; ${ }^{\#}$ compared by Chi-square test; ${ }^{\dagger}$ compared by Fisher exact test. 
Table 2 (on next page)

The positive detection rates of human brucellosis infection from different sources 
Table 2. The percentages of test positive for human brucellosis from different sources

\begin{tabular}{|c|c|c|c|c|c|c|c|}
\hline \multirow[b]{2}{*}{ Characteristics } & \multirow{2}{*}{$\begin{array}{c}\text { Total } \\
(\mathrm{N}=2247)\end{array}$} & \multirow{2}{*}{$\begin{array}{c}\text { Active } \\
(\mathrm{n}=1249)\end{array}$} & \multirow{2}{*}{$\begin{array}{l}\text { Passive } \\
(\mathrm{n}=998)\end{array}$} & \multirow[b]{2}{*}{$p$} & \multicolumn{3}{|c|}{ Passive } \\
\hline & & & & & $\begin{array}{l}\text { From hospital } \\
\quad(\mathrm{n}=480)\end{array}$ & $\begin{array}{c}\text { From CDC } \\
(n=518)\end{array}$ & $p$ \\
\hline All the participants & $299(13.3)$ & $256(20.5)$ & $43(4.3)$ & $<0.001$ & $37(7.7)$ & $6(1.2)$ & $<0.001$ \\
\hline \multicolumn{8}{|l|}{ Age, year } \\
\hline$\leq 45$ & $100(10.4)$ & $82(14.6)$ & $18(4.6)$ & $<0.001$ & $13(7.2)$ & $5(2.3)$ & 0.021 \\
\hline $45 \sim 60$ & $124(13.8)$ & $112(24.3)$ & $12(2.7)$ & $<0.001$ & $11(6)$ & $1(0.4)$ & $<0.001$ \\
\hline$>60$ & $75(19.3)$ & $62(27.6)$ & $13(8.0)$ & $<0.001$ & $13(11.2)$ & $0(0)$ & 0.021 \\
\hline \multicolumn{8}{|l|}{ Sex } \\
\hline Male & $218(14.5)$ & $186(22.1)$ & $32(4.8)$ & $<0.001$ & $26(9.3)$ & $6(1.6)$ & $<0.001$ \\
\hline Female & $81(10.9)$ & $70(17.2)$ & $11(3.3)$ & $<0.001$ & $11(5.5)$ & $0(0)$ & 0.004 \\
\hline \multicolumn{8}{|l|}{ Ethnicity } \\
\hline Han & $282(13.0)$ & $240(20.1)$ & $42(4.3)$ & $<0.001$ & $36(7.6)$ & $6(1.2)$ & $<0.001$ \\
\hline Hui & $17(23.3)$ & $16(29.6)$ & $1(5.3)$ & 0.032 & $1(14.3)$ & $0(0)$ & 0.368 \\
\hline \multicolumn{8}{|l|}{ Education } \\
\hline Under junior middle school & $117(18.5)$ & $103(27.2)$ & $14(5.5)$ & $<0.001$ & $14(8.4)$ & $0(0)$ & 0.003 \\
\hline Junior middle school & $148(12.4)$ & $125(20.2)$ & $23(4.0)$ & $<0.001$ & $18(9.0)$ & $5(1.3)$ & $<0.001$ \\
\hline Above junior middle school & $34(8.1)$ & $28(11.2)$ & $6(3.6)$ & 0.006 & $5(4.5)$ & $1(1.8)$ & 0.665 \\
\hline \multicolumn{8}{|l|}{ Career } \\
\hline Famer & $219(19.5)$ & $197(26.6)$ & $22(5.8)$ & $<0.001$ & $22(10)$ & $0(0)$ & $<0.001$ \\
\hline Worker & $34(4.8)$ & $22(8.2)$ & $12(2.7)$ & 0.002 & $6(5.6)$ & $6(1.8)$ & 0.045 \\
\hline Children/Student & $8(14.8)$ & $7(22.6)$ & $1(4.4)$ & 0.119 & $1(4.4)$ & $0(0)$ & 1.000 \\
\hline Veterinarian & $6(10.2)$ & $5(13.9)$ & $1(4.4)$ & 0.389 & $1(100)$ & $0(0)$ & 0.043 \\
\hline Other & $32(10.5)$ & $25(14.3)$ & $7(5.4)$ & 0.013 & $7(5.5)$ & $0(0)$ & 1.000 \\
\hline Contact history of sheep or cow & & & & & & & \\
\hline
\end{tabular}




\begin{tabular}{lccccccc}
\hline Yes & $251(16.0)$ & $216(23.3)$ & $35(5.5)$ & $<0.001$ & $29(21.5)$ & $6(1.2)$ & $<0.001$ \\
Cultivation & $162(14.3)$ & $133(21.2)$ & $29(5.7)$ & $<0.001$ & $23(21.9)$ & $6(1.5)$ & $<0.001$ \\
Slaughter & $56(21.1)$ & $54(28.4)$ & $2(2.6)$ & $<0.001$ & $2(20.0)$ & $0(0)$ & 0.016 \\
Selling & $28(18.5)$ & $27(26.5)$ & $1(2)$ & $<0.001$ & $1(12.5)$ & $0(0)$ & 0.163 \\
Process & $12(17.4)$ & $9(22.5)$ & $3(10.3)$ & 0.218 & $3(20.0)$ & $0(0)$ & 0.224 \\
No & $48(7)$ & $40(12.5)$ & $8(2.2)$ & $<0.001$ & $8(2.3)$ & $0(0)$ & 1.000 \\
Clinical manifestation & $265(18.5)$ & $226(23.6)$ & $39(8.2)$ & $<0.001$ & $37(7.8)$ & $2(100)$ & 0.006 \\
Fever & $197(19.3)$ & $171(28.1)$ & $26(6.3)$ & $<0.001$ & $26(6.3)$ & $0(0)$ & 1.000 \\
Arthralgia & $130(20.9)$ & $104(22.2)$ & $26(16.8)$ & 0.148 & $26(16.8)$ & $0(0)$ & 1.000 \\
Debilitation & $93(20.0)$ & $79(22.1)$ & $14(13.0)$ & 0.037 & $12(11.3)$ & $2(100)$ & 0.016 \\
Hyperhidrosis & $102(30.0)$ & $92(34.6)$ & $10(13.5)$ & $<0.001$ & $10(13.5)$ & $0(0)$ & 1.000 \\
Muscle pain & $93(28.4)$ & $83(32.1)$ & $10(14.7)$ & 0.004 & $8(12.1)$ & $2(100)$ & 0.020 \\
Other & $8(5.9)$ & $5(7.4)$ & $3(4.5)$ & 0.718 & $3(4.5)$ & $0(0)$ & 1.000 \\
\hline
\end{tabular}




\section{Table 3(on next page)}

The independent factors related to the positive detection of human brucellosis in the active and passive detection groups 
Table 3. The independent factors related to the positive detection of human brucellosis in the active and passive detection groups

\begin{tabular}{|c|c|c|c|c|c|c|}
\hline \multirow{2}{*}{ Characteristics } & \multicolumn{2}{|l|}{ Total } & \multicolumn{2}{|c|}{ Active detection group } & \multicolumn{2}{|c|}{ Passive detection group } \\
\hline & OR $(95 \% \mathrm{CI})$ & $p$ & OR $(95 \% \mathrm{CI})$ & $p$ & OR $(95 \% \mathrm{CI})$ & $p$ \\
\hline \multicolumn{7}{|l|}{ Age, year } \\
\hline$\leq 45$ & Reference & & Reference & & Reference & \\
\hline $45 \sim 60$ & $1.2(0.87-1.65)$ & 0.262 & $1.40(0.99-2.00)$ & 0.060 & $0.42(0.18-0.98)$ & 0.044 \\
\hline$>60$ & $1.34(0.89-2.02)$ & 0.167 & $1.40(0.88-2.23)$ & 0.152 & $0.80(0.30-2.14)$ & 0.657 \\
\hline \multicolumn{7}{|l|}{ Sex } \\
\hline Male & $1.48(1.09-2.01)$ & 0.011 & $1.41(1.01-1.98)$ & 0.043 & $2.19(0.94-5.13)$ & 0.070 \\
\hline Female & Reference & & Reference & & Reference & \\
\hline \multicolumn{7}{|l|}{ Ethnicity } \\
\hline Han & $0.71(0.38-1.33)$ & 0.281 & $0.71(0.37-1.38)$ & 0.314 & $0.66(0.06-7.18)$ & 0.729 \\
\hline Hui & Reference & & Reference & & Reference & \\
\hline \multicolumn{7}{|l|}{ Education } \\
\hline Under junior middle school & Reference & & Reference & & Reference & \\
\hline Junior middle school & $0.93(0.67-1.29)$ & 0.658 & $0.85(0.59-1.21)$ & 0.367 & $1.03(0.42-2.55)$ & 0.944 \\
\hline Above junior middle school & $0.72(0.44-1.17)$ & 0.185 & $0.64(0.37-1.11)$ & 0.113 & $1.06(0.31-3.61)$ & 0.927 \\
\hline \multicolumn{7}{|l|}{ Career } \\
\hline Worker & Reference & & Reference & & Reference & \\
\hline Farmer & $2.39(1.54-3.69)$ & $<0.001$ & $2.66(1.58-4.50)$ & $<0.001$ & $1.39(0.52-3.68)$ & 0.511 \\
\hline Children/Student & $1.51(0.6-3.85)$ & 0.383 & $1.74(0.62-4.93)$ & 0.294 & $0.74(0.04-12.93)$ & 0.835 \\
\hline Veterinarian & $1.97(0.75-5.15)$ & 0.169 & $2.38(0.80-7.05)$ & 0.118 & $2.01(0.24-17.08)$ & 0.523 \\
\hline Other & $1.72(0.96-3.08)$ & 0.067 & $1.59(0.80-3.15)$ & 0.182 & $2.57(0.75-8.80)$ & 0.133 \\
\hline \multicolumn{7}{|l|}{ Contact history of sheep or cow } \\
\hline Cultivation & $1.78(1.28-2.47)$ & 0.001 & $1.43(0.99-2.07)$ & 0.054 & $7.44(2.87-19.25)$ & $<0.001$ \\
\hline Slaughter & $1.85(1.23-2.79)$ & 0.003 & $1.98(1.26-3.09)$ & 0.003 & $0.95(0.17-5.23)$ & 0.951 \\
\hline Selling & $2.58(1.49-4.48)$ & 0.001 & $2.37(1.32-4.22)$ & 0.004 & $3.71(0.36-38.8)$ & 0.273 \\
\hline
\end{tabular}




\begin{tabular}{lcccccc}
\hline Process & $2.37(1.1-5.1)$ & 0.028 & $1.92(0.78-4.73)$ & 0.157 & $4.60(0.74-28.38)$ & 0.100 \\
Clinical manifestation & & & & & & \\
$\quad$ & $2.04(1.51-2.76)$ & $<0.001$ & $1.91(1.38-2.65)$ & $<0.001$ & $1.67(0.700-4.00)$ & 0.246 \\
$\quad$ Fever & $1.28(0.96-1.69)$ & 0.087 & $0.9(0.66-1.23)$ & 0.509 & $10.35(4.63-23.15)$ & $<0.001$ \\
Arthralgia & $0.84(0.61-1.15)$ & 0.281 & $0.76(0.54-1.06)$ & 0.105 & $1.97(0.78-4.95)$ & 0.152 \\
Debilitation & $1.81(1.3-2.52)$ & $<0.001$ & $1.91(1.34-2.73)$ & $<0.001$ & $1.47(0.50-4.35)$ & 0.481 \\
Hyperhidrosis & $1.69(1.23-2.33)$ & 0.001 & $1.55(1.10-2.18)$ & 0.013 & $1.80(0.61-5.34)$ & 0.291 \\
Muscle pain & $0.41(0.19-0.87)$ & 0.02 & $0.29(0.11-0.75)$ & 0.011 & $1.37(0.35-5.30)$ & 0.651 \\
$\quad$ Other & & & & & & \\
Population source & $3.45(2.41-4.96)$ & $<0.001$ & & & & \\
$\quad$ Active detection group & Reference & & & & & \\
$\quad$ Passive detection group &
\end{tabular}

OR, odds ratio; CI, confidence interval. Other clinical manifestation includes headache, anemia, diarrhea, thrombocytopenia, rash, loss of consciousness, vomit and edema. 
Figure 1

The flowchart of the enrollment of all people tested for brucellosis from different sources during January to December 2018 in Jining City

The flowchart of the enrollment of all people tested for brucellosis from different sources during January to December 2018 in Jining City

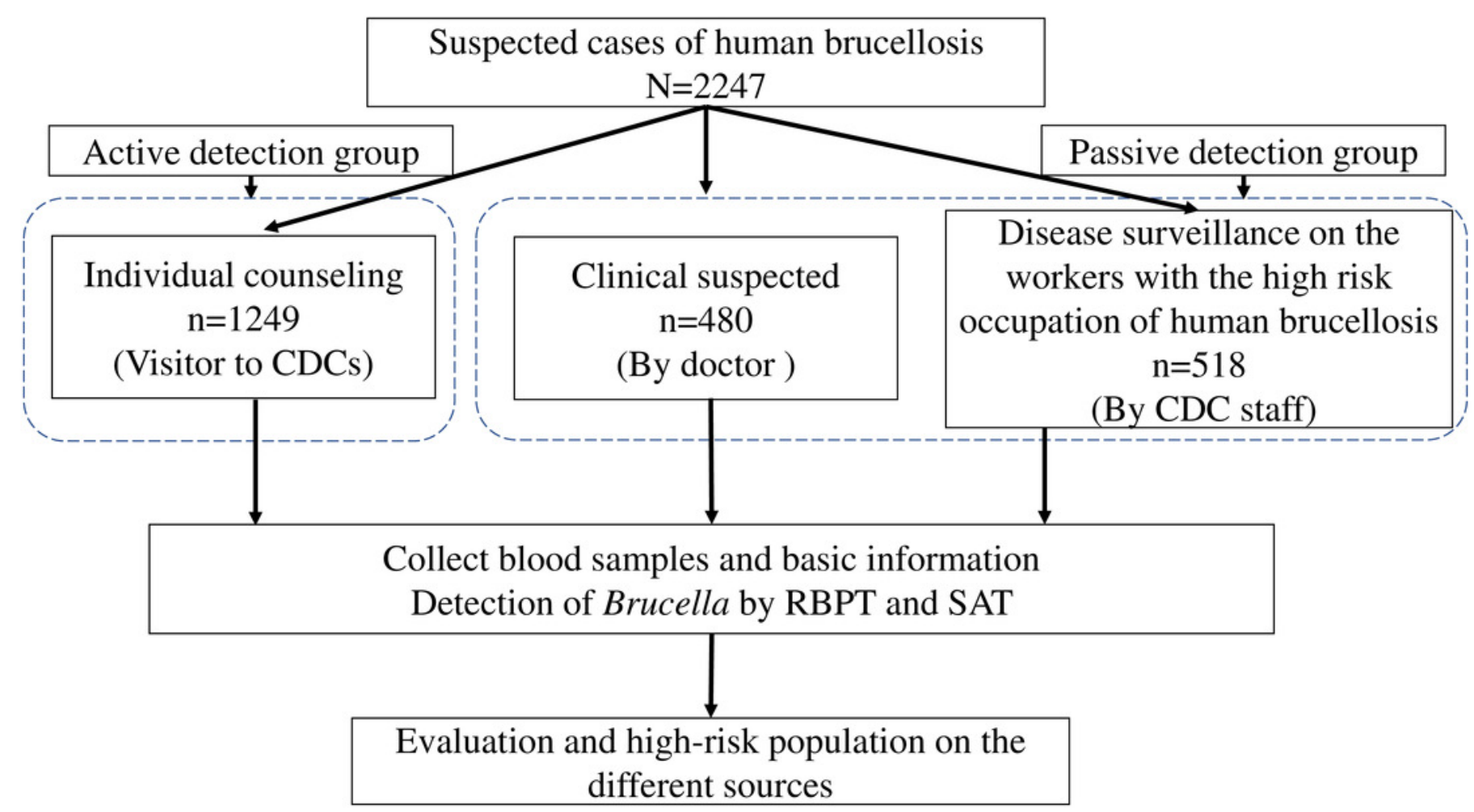

